\title{
Abdominal-thoracic respiratory movements and levels of arousal*
}

\author{
BEVERLY TIMMONS, JOSEPH SALAMY, JOE KAMIYA \\ and DEXTER GIRTON \\ Langley Porter Neuropsychiatric Institute, San Francisco, Calif. 94122
}

Respiratory movements of the abdomen and chest of human Ss were found to undergo progressive changes with loss of wakefulness. Abdominal-dominant breathing was associated with relaxed wakefulness, abdominal-thoracic equality with drowsiness, and thoracic-dominant breathing with sleep onset. During drowsiness, variations in amplitude of abdominal movements were closely related to vacillations between alpha and theta activity in the EEG.

Breathing patterns are considered to be closely related to states of consciousness in the meditative disciplines of the East. European respiration therapists have observed individual differences in breathing patterns and regard them to be reliable indicators of psychological states (Proskauer, 1968). Observations from these disciplines and from clinicians (Clausen, 1951) indicate that the relative amplitude of abdominal and thoracic movements may be one of the most significant aspects of respiration with regard to psychophysiological states. This parameter of respiration has received relatively little attention from behavioral scientists. 1 Sleep researchers have indicated that the abdominal-thoracic ratio may be different during the waking state as compared to sleep, but the findings are inconsistent (Kleitman, 1963; Goldie \& Green, 1961). Clausen (1951) reported differences in abdominal-thoracic relationships among groups of normal, neurotic, and psychotic Ss. Goldie \& Green (1961) saw a change in abdominal-thoracic ratio during hypnosis and suggested that in the absence of other objective evidence, it could be used as the first sign of the hypnotic mode.

The present study was an attempt to elucidate the relationship between abdominal-thoracic respiratory movements and the electrophysiological state of consciousness as indicated by the EEG.

SUBJECTS AND PROCEDURE

Eleven young adults (10 males, 1 female) with no history of sleep disturbances served as Ss. Each $\mathrm{S}$ participated in one recording session, which lasted approximately $45 \mathrm{~min}$. The experiments were conducted during the afternoon in a

* This study was supported by the Advanced Research Projects Agency of the Department of Defense and was monitored by the Office of Naval Research under Contract No. N 00014-70-C-1950 to the San Diego State College Foundation. semidarkened room. After the recording electrodes were applied, Ss reclined in a supine position and were instructed to relax and go to sleep.

\section{APPARATUS}

The EEG was recorded from a left-central/left-occipital placement, and eye movements from electrodes placed at the nasion and outer canthius of the left eye. Respiratory movements were monitored with mercury thread strain gauges ${ }^{2}$ stretched to $32 \mathrm{~cm}$ in length and taped at both ends to the S's body. The thoracic gauge was placed across the chest at the level of the armpits, and the abdominal gauge was placed just below the navel.

\section{RESULTS}

As the EEG indicated a transition from the relaxed waking state to Stages 1 and 2 sleep, there were distinctive and systematic changes in abdominal and thoracic respiratory movements.

Changes in Abdominal and Thoracic Amplitudes

The relaxed waking state, characterized by an abundance of alpha activity $(8-13 \mathrm{~Hz})$, was associated with a breathing pattern in which the amplitudes of abdominal movement exceeded those of the thorax in 10 of 11 Ss (Fig. la, Table 1).

Changes in the pattern of breathing were observed as EEG indications of drowsiness appeared, viz, vacillations in the EEG between alpha activity and a low-voltage mixed pattern with theta activity, accompanied by slow eye movements. The relation between EEG fluctuations and changes in breathing pattern were determined by comparing the amplitudes of the two breath cycles immediately preceding and following an EEG transition. Such transitions were defined as a dropout of alpha activity for a period of at least $10 \mathrm{sec}$ duration (alpha-theta transition), or the return of alpha rhythm for at least $5 \mathrm{sec}$ (theta-alpha transition). A reduction of the amplitude of abdominal movements occurred with $93 \%$ of the alpha-theta transitions (Fig. 1b), and an enhancement of abdominal amplitude with $81 \%$ of the theta-alpha transitions (Fig. 1c). Table 2 shows the frequency with which the succeeding abdominal cycle amplitude decreased or increased following an EEG transition. Thoracic amplitudes were not closely related to the alpha-theta transitions. In some Ss, the slow eye movements characteristic of drowsiness (Aserinsky \& Kleitman, 1955) preceded the EEG-abdominal amplitude changes; in others, they were simultaneous or occurred slightly later.

Throughout the period of drowsiness and Stage 1,3 a tonic decrease in abdominal breath cycle amplitudes and a concomitant increase in thoracic amplitudes occurred. As a result, the abdominal and thoracic excursions became virtually equal. All 11 Ss displayed this equality at times during the recording. In $9 \mathrm{Ss}$, it was present at the onset of Stage 1 (see Table 2). There was much individual variation in the amount of time Ss remained in the drowsy state and Stage 1, during which they vacillated between alpha and the low-voltage mixed pattern with theta and between a b d o minal-dom in ant and abdominal-equal-to-thoracic modes of breathing.

Thoracic amplitudes increased gradually during drowsiness and Stage 1, until finally a thoracic-dominant mode of breathing emerged (Fig. 1d). This mode generally developed in late Stage 1 or early Stage 2. It was seen in $10 \mathrm{Ss}$ (although only 6 Ss attained Stage 2). EEG arousals (alpha bursts) occurring during thoracic-dominant breathing were associated with immediate resumption of the abdominal-dominant mode of respiration (analogous to the effect of arousal during the abdominal-equal-to-thoracic mode described above).

Changes in

\section{Inspiratory-Expiratory} Phase Durations

In 7 of $11 \mathrm{Ss}$, the inspiratory phase of the abdominal breath cycle was of longer duration than the expiratory phase in the waking state. ${ }^{4}$ At the onset of Stage 1, inspiratory and expiratory phases were virtually equal in 8 Ss (Fig. 1b). At onset of Stage 2 , 5 of 6 Ss continued to display this equality of phases.

Thoracic phase durations were difficult to judge during the waking state because of the low amplitude and indefinite form of the cycle. As thoracic amplitudes increased with drowsiness and onset of sleep, however, a more definite waveform emerged. When the thoracic respiratory movements were of greater 


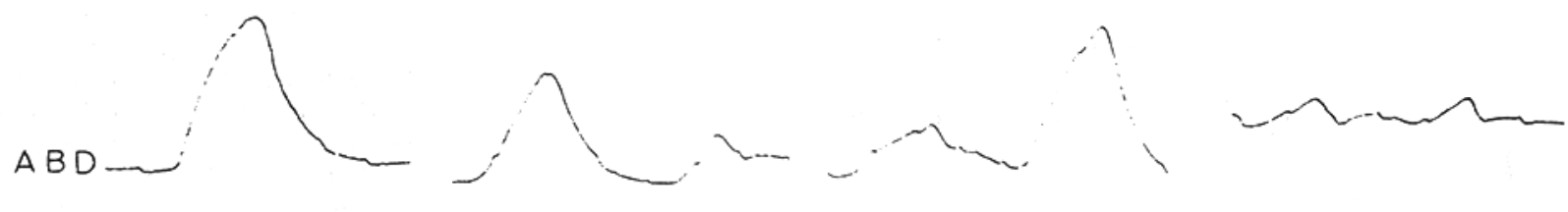

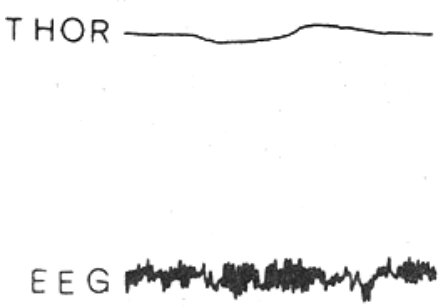

a
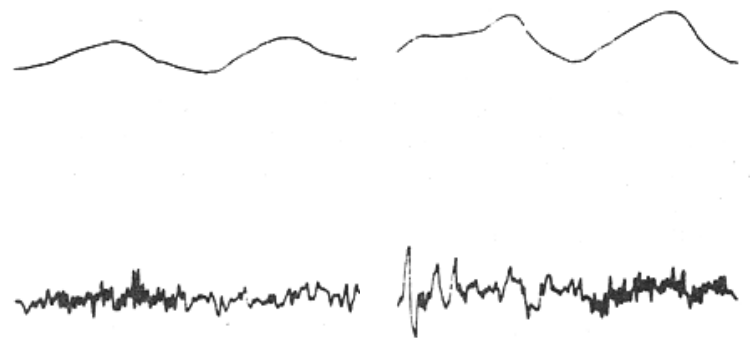

b
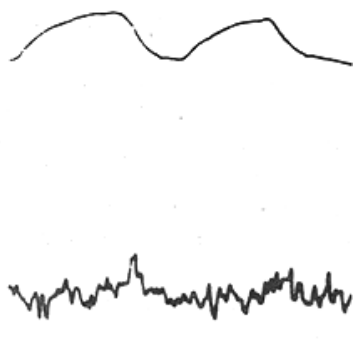

C

Fig. 1. Abdominal and thoracic respiratory movements at various levels of arousal.

Table 1

Number of Ss Displaying Each Pattern of Respiratory Movement at Each EEG Stage*

\begin{tabular}{|c|c|c|c|}
\hline & $\begin{array}{c}\text { Abdominal- } \\
\text { Dominant }\end{array}$ & $\begin{array}{c}\text { Abdominal } \\
\text { Equal (or } \\
\text { Approximately } \\
\text { Equal) to } \\
\text { Thoracic }\end{array}$ & $\begin{array}{l}\text { Thoracic- } \\
\text { Dominant }\end{array}$ \\
\hline Initial Waking State & 10 & 1 & $0 \div$ \\
\hline Onset Stage 1 & 1 & 9 & $1+\div$ \\
\hline Onset Stage 2 & 1 & 2 & 3 \\
\hline
\end{tabular}

* The initial 30-sec epoch of the first appearance of each stage was observed.

$\div$ An additional $S$ displayed thoracic-dominant breathing later in the wake recording. $++F i v e$ additional Ss showed thoracic-dominant breathing later in $S$ tage 1 but did not progress to Stage 2.

Table 2

Incidence of Changes in Abdominal Respiratory Movements Following EEG Transitions*

\begin{tabular}{cccc}
\hline & $\begin{array}{c}\text { Increase in } \\
\text { Abdominal } \\
\text { Amplitude }\end{array}$ & $\begin{array}{l}\text { Decrease in } \\
\text { Abdominal } \\
\text { Amplitude }\end{array}$ & $\begin{array}{c}\text { No Change in } \\
\text { Abdominal } \\
\text { Amplitude }\end{array}$ \\
\hline $\begin{array}{c}\text { Alpha-Theta } \\
\text { Theta-Alpha }\end{array}$ & 2 & 51 & 2 \\
8
\end{tabular}

*Totals for $11 \mathrm{Ss}$

amplitude than those of the abdomen, the thoracic inspiratory phase was consistently of longer duration than the expiratory. Also, the form of the thoracic breath cycle generally assumed a distinctive "skewed dome" shape at this time (see Fig. 1d).

$$
\text { DISCUSSION }
$$

Our findings are in accord with those of Goldie \& Green (1961), who observed that the predominant mode of breathing during light sleep was thoracic, and with arousal it became abdominal. 5 In addition, we found that during drowsiness and Stage 1, there was a striking parallelism between the transient changes in brain states and respiratory movements. Bülow (1963) found the transient EEG changes of drowsiness to be similarly associated with changes in ventilation 6 : "When the alpha activity in the EEG disappeared and theta waves developed, ventilation decreased. When the alpha activity reappeared sporadically, ventilation again increased [p. 31].," The present findings suggest that changes in ventilation may be effected by changes in relative dominance of abdominal or thoracic modes of breathing.

The present study also supports the contention of Goldie and Green that changes in mode of breathing may be a useful adjunct to the EEG in defining levels of consciousness. For example, our data may make possible a finer differentiation of the transitional state from the earliest signs of loss of wakefulness to the onset of sleep.
Observations of respiratory parameters may also be particularly relevant to the study of meditative states and hypnagogic imagery. EEGs recorded during various types of meditation have generally shown patterns compatible with relaxed wakefulness or drowsiness (see Timmons \& Kamiya, 1970). Green, Green, \& Walters (1970) have observed that the hypnagogic reverie state is accompanied by a "slowed alpha-theta" pattern. In the present study, this EEG pattern (see Fig. 1b) was observed to be associated with characteristic respiratory patterns: vacillation between abdominaldominant and abdominal-equal-tothoracic breathing, and equality of abdominal inspiratory and expiratory phase durations.

Since spontaneous changes in consciousness, i.e., the process of sleep onset, are accompanied by specific respiratory patterns, it seems reasonable that self-manipulation of these patterns might be useful as a means of voluntarily altering states of consciousness. A precedent for this approach is found in the meditative disciplines which have traditionally emphasized breathing practices of various types. Biofeedback techniques $^{7}$ might be effective in training individuals to maintain specified respiratory patterns. ${ }^{8}$

\section{REFERENCES}

ASERINSKY, E.. \& KLEITMAN, N. Two types of ocular motility occurring in sleep. Journal of Applied Physiology, $1955,8,1-10$.

BARACH. A. L., \& SEAMAN, W. B. Role of the diaphragm in chronic pulmonary emphysema. New York Journal of Medicine, $1963,63,415-417$.

BLOCK. J. D., LAGERSON, J., ZOHMAN, 
L. R.. \& KELLY, G. A feedback device for teaching diaphragmatic breathing. American Review of Respiratory Disease. $1969,100,577-578$

BÜLOW, K. Respiration and wakefulness in man. Acta Physiologica Scandinavica. 1963, 59, Suppl. 209, 1-110.

CLAUSEN, J. Respiration movement in normal, neurotic and psychotic subjects. Acta Psychiatrica et Neurologica, 1951. Suppl. 68, 1.74.

GOLDIE, L., \& GREEN, J. M. Changes in mode of respiration as an indication of level of awareness. Nature, 1961, 189. 581-582.

GREEN, E., GREEN, A. M.. \& WALTERS E. D. Self-regulation of internal states. In J. Rose (Ed.), Progress of cybernetics. Proceedings of the international congress of cybernetics, London, 1969. London: Gordon \& Breach, 1970. Pp. 1299-1317.

KLEITMAN, N. Sleep and wakefulness. (2nd ed.) Chicago: University of Chicago Press, 1963.
PROSKAUER. M. Breathing therapy. In E. Otto and J. Mann (Eds.), Ways of growth. New York: Grossman, 1968.

RECHTSCHAFFEN, A., \& KALES, A. (Eds.) A manual of standardized terminology, techniques and scoring system for sleep stages of human subjects. Washington, D.C: U.S. Government Printing office, National Institutes of Health Publication No. 204, 1968.

TIMMONS, B. \& KAMIYA J. The psychology and physiology of meditation and related phenomena: A bibliography. Journal of Transpersonal Psychology, $1970,2,41-59$.

\section{NOTES}

1. Physicians recognize that some types of pathology are associated with specific modes of breathing (see Barach \& Seaman, 1963).

2. Parks Electronics, Beaverton, Oreg. 97005. Specially designed dc amplifiers and techniques of recording will be described in a subsequent paper.

3 EEG states were defined according to the criteria set forth by Rechtschaffen \& Kales (1968). Stage $I$ is characterized by a record containing less than 50\% alpha combined with low-voltage activity in a 30-sec epoch.

4. Inspiration = expansion, expiration = contraction of the abdominal or thoracic region.

5. Inconsistent results in previous studies of abdominal-thoracic ratios and sleep (see Kleitman, 1963, p. 48) may be due to absence of simultaneous EEG observations, with the exception of the Goldie and Green study.

6. As measured by spirometry (L/min).

7. Such techniques augment the sensory feedback from the physiological activity and provide assistance in enhancing voluntary control of the activity.

8. Feedback training is already in use to help emphysema patients suppress thoracic breathing (see Block et al, 1969). 